\title{
The Treatment of Refractory Pituitary Adenomas
}

\author{
Congxin $\mathrm{Dai}^{\dagger}$, Xiaohai Liu ${ }^{\dagger}$, Wenbin Ma and Renzhi Wang* \\ Department of Neurosurgery, Peking Union Medical College Hospital, Chinese Academy of Medical Sciences \& Peking Union \\ Medical College Beijing, Beijing, China
}

Refractory pituitary adenomas (PAs) are defined as aggressive-invasive PAs characterized by a high Ki-67 index, rapid growth, frequent recurrence, and resistance to conventional treatments. It is notoriously difficult to manage refractory PAs because the efficacy of current therapeutic options is limited. The purpose of this review is to address currently employed and promising therapeutic strategies for the treatment of refractory PAs. Except for prolactinomas, neurosurgery is the first-line option, but most refractory PAs often recur or re-grow after initial surgery and require further treatments. Medical therapy, radiotherapy and re-operation are explored when surgery has failed to completely resect tumors; however, refractory PAs are usually resistant to these treatments. As a salvage treatment, temozolomide (TMZ) has shown promising results

OPEN ACCESS

Edited by:

Adam Mamelak,

Cedars-Sinai Medical Center,

United States

Reviewed by:

Moises Mercado,

Mexican Social Security Institute (IMSS), Mexico

Mirtha Adriana Guitelman,

Durand Hospital, Argentina

*Correspondence: Renzhi Wang wangrz@126.com

tThese authors have contributed equally to this work

Specialty section: This article was submitted to Pituitary Endocrinology, a section of the journal Frontiers in Endocrinology

Received: 27 November 2018 Accepted: 09 May 2019 Published: 29 May 2019

Citation:

Dai C, Liu X, Ma W and Wang R (2019)

The Treatment of Refractory Pituitary Adenomas. Front. Endocrinol. 10:334. doi: 10.3389/fendo.2019.00334 and is currently used for all types of refractory PAs. However, not all refractory PAs are responsive to TMZ treatment, and some of these PAs are resistant to TMZ. Although targeted therapies such as vascular endothelial growth factor, epidermal growth factor and mTOR inhibitors have also been used to treat refractory PAs, the effectiveness of these targeted therapies is still not known due to a lack of data from randomized prospective trials. As a novel therapeutic method, cancer immunotherapy is a promising strategy for the treatment of refractory PAs, but further preclinical research and clinical trials are needed to assess the efficacy of this new approach. In summary, early identification and a multidisciplinary approach are required to treat refractory PAs.

Keywords: refractory pituitary adenomas, surgical treatment, medical therapy, radiotherapy, temozolomide, targeted therapy, immunotherapy

\section{INTRODUCTION}

Most pituitary adenomas (PAs) are benign and exhibit slow expansive growth; however, approximately $35 \%$ of pituitary adenomas are invasive and some of them exhibit more aggressive clinical behavior with high rates of recurrences $(1,2)$. In the clinic, a subset of aggressiveinvasive PAs characterized by a high Ki-67 index, rapid growth, frequent recurrence, and resistance to conventional treatments is defined as refractory PAs (3). The definition of refractory pituitary adenomas includes radiological finding, histopathological, and clinical features. Trouillas et al. (4) also performed a retrospective multicentric study and proved that Ki-67 and other proliferation parameters could be used to define aggressive tumors, which is similar to our proposal. They classified PAs 5 grades (grade 1a: non-invasive, 1b: non-invasive and proliferative, 2a: invasive, 2b: invasive and proliferative, and 3: metastatic) based on tumor size, type, invasion, P53 and markers of the cell cycle (Ki-67). After 8-year follow-up, they found that invasive and proliferative tumors (grade $2 \mathrm{~b}$ ) had a poor prognosis compared to non-invasive tumors. These refractory PAs often have a very poor prognosis and even have a fatal outcome. 
However, there is no general agreement on how to manage patients with refractory PAs. For neurosurgeons and clinicians, it is difficult to choose the optimal therapeutic options in the treatment of refractory PAs. Therefore, to improve the prognoses of these patients, it is very important and necessary to review the emerging treatments for refractory PAs.

\section{MANAGEMENT OF REFRACTORY PAS}

\section{Surgical Treatment}

Typically, multimodal approaches are required to manage refractory PAs. Other than prolactin-secreting adenomas (PRLomas), which should first be treated with dopamine agonists (DAs), the primary treatment option is usually surgery. Most refractory PAs are largely invasive and infiltrate the adjacent tissues, surgery is usually unable to cure or control them (5). However, the therapeutic goals of surgery are maximum reduction in tumor mass, decompression of visual pathways, best possible reduction in hormonal oversecretion, amelioration of clinical symptoms and release of complications (6). After the primary operation, refractory PAs always recur or re-grow early, and need further surgical intervention. Although repeated surgery seldom achieves complete excision. it is still necessary to relieve compressive symptoms.

Dopamine agonists are the first treatment of choice for prolactinomas, however, resistance to dopamine agonists occurs in a subset of patients with PRL-omas.

TSS surgery is recommended for an important therapeutic option for these resistant prolactinomas. In a retrospective study, Primeau et al. (7) analyzed outcomes of patients with a prolactinoma treated by TSS, and found that postoperative remission was obtained in $63 \%$ of microprolactinomas, $60 \%$ of noninvasive macroprolactinomas, and none of the invasive macroprolactinomas. However, after surgical remission, a recurrence of hyperprolactinemia was observed in one-third of prolactinoma patients after a median follow-up period of 36 (7-164) months. Another retrospective study indicated that normalization of prolactin occurred in $87 \%$ of patients with microadenomas and in $56 \%$ of macroadenomas after surgery, and recurrence of hyperprolactinemia occurred in $13 \%$ of them at 10 years follow-up (8).

Although repeat TSS is less effective for residual and recurrent pituitary adenomas, it may still be beneficial for many patients by reducing mass effect or adenoma burden to improve the effectiveness of adjuvant therapies. Vargas (9) carried out a retrospective study on treatment outcome of 485 Patients with NFPA, the results indicated that after first surgery, 27.2\% (127/466) found to have tumor persistence, and second pituitary surgery was performed in these 127 patients, $23.6 \%$ (30/127) of them were documented with tumor persistence and need third operation. In 2016, a systematic review and evidencebased guideline for residual or recurrent NFPAs was published by the Congress of Neurological Surgeons, and repeat resection is listed as a level III recommendation for the treatment of symptomatic recurrent or residual NFPAs (10). Mercado (11) reported that the presence of extension into the cavernous sinus and of an adenoma remnant after initial surgery associated with recurrence. Espinosa De Los Monteros et al. (12) also evaluated the outcome of surgical reintervention in patients with active acromegaly, and found that only 9\% (5/53) of patients achieved complete biochemical cure. Almeida et al. (13) assessed the outcomes of reoperation for patients with residual or recurrent growth hormone-secreting pituitary adenoma at the authors' institution, and no statistically significant difference was found in disease control rates between the patients who underwent reoperation and first-time neurosurgery. They further systematically reviewed 161 reoperations and 2,189 firsttime surgery cases retrieved from 29 papers and found that reoperation and first-time surgery had similar control rates for microadenomas but that reoperation was related to substantially lower control rates for macroadenomas $(27.5 \%)$ and tumors invading the cavernous sinus (14.7\%). Mendoza et al. (14) evaluated the long-term efficacy of the different secondary interventions for persistent and recurrent Cushing's disease, and found that early remissions were observed in $66.6 \%$ of the reoperated patients, and a long-lasting remission was achieved in only $33.3 \%$ patients. However, the rate of complications including transient diabetes insipidus, and arachnoid tear related to surgical reintervention was raised with the increasing times of operation. Because of the relatively small numbers of reported recurrences of $\mathrm{CD}$ and incompletely reported complications, whether significant differences exist in complications between primary and repeat resections is still controversial (15).

The comparison of microscopic and endoscopic approaches for recurrent or residual PAs remains controversial. Heringer et al. (16) performed a meta-analysis to evaluate the effect of repeated TSS in recurrent or residual PAs and found that half of secreting tumors and more than half of nonfunctioning PAs (NFPAs) could achieve remission after surgery, and that there is no difference between the endoscopic and microscopic approach. However, Esquenazi et al. performed another metaanalysis to compare the effects of endoscopic and microscopic TSS on recurrent and/or residual PAs, and found that endoscopic surgery led to modest increases in resection rates on residual or recurrent adenomas (17). Do et al. (18) retrospectively analyzed 61 patients with recurrent or residual PAs who underwent endoscopic endonasal surgery and found that gross total resection was achieved in 31 patients (51.7\%), indicating that the endoscopic endonasal approach is a safe and effective option for recurrent PAs. The results from another meta-analysis performed by Li and colleagues also indicated that endoscopic surgery is related to higher gross tumor removal and lower incidence of complications in patients with PAs (19). Based on previous studies and our experience, endoscopic surgery is better than microscopic surgery for recurrent PAs; however, these findings need to be verified by large-scale prospective randomized controlled trials.

Therefore, maximum tumor resection, while preserving nerve function, is necessary to achieve local control and decompress vital structures for refractory PAs with compressive symptoms.

\section{Radiation Therapy}

Despite the success of TSS or maximum tumor resection, most refractory PAs will re-grow or recur; therefore, other 
therapeutic approaches are usually needed. If surgical and/or medical therapy failed to control the tumor growth, radiation therapy (RT) is currently the next treatment option. There are several RT options for patients with refractory PAs. Conventional external beam radiotherapy (EBRT) has been used to treat pituitary adenomas for several decades and has shown good clinical safety and efficacy. However, EBRT can result in significant complications, such as hypopituitarism, cognitive function deficiency and cerebrovascular disease (20). In recent years, EBRT has largely been replaced by the stereotactic radiosurgery (SRS) and fractionated stereotactic radiotherapy (FSRT). Stereotactic radiosurgery (SRS) is the delivery of a single high dose of radiation under conditions of accurate positioning. As new methods of radiation delivery, SRS and FSRT could minimize these complications. Recently, SRS has been gaining popularity because it minimizes the exposure of normal brain tissue to radiation. SRS has been preferred over EBRT because of the convenience of single-day therapy and the potential for a faster effect on the tumor (21). A variety of SRSs, including Gamma Knife radiosurgery (GKRS), CyberKnife (CK) and proton beam RT, are available to deliver stereotactic RT.

Comparing EBRT and SRS may help guide decision making for patients with residual or recurrent pituitary tumors. Kong et al. (22) compared the efficacy and safety of SRS and EBRT for the treatment of 125 patients with PAs. Although no significant difference was found in either biochemical remission or tumor growth control, the time to biochemical remission after SRS was much shorter than that following EBRT (26 vs. 63 months).

To better understand the effects of SRS for Cushing's disease (CD), 23. Mehta et al. (23) performed an international, multicenter, retrospective cohort analysis that included 278 patients with CD who received SRS and found that the overall rate of durable control of hypercortisolism was $64 \%$ at 10 years; in addition, adverse radiation effects including hypopituitarism (25\%) and cranial neuropathy (3\%) were observed. However, recurrences occurred in $18 \%$ of the patients with initial cortisol normalization. In one prospective study, GKRS-induced hypopituitarism occurred in $58.3 \%$ of patients with a recurrent or residual acromegaly or CD (24). CK is a frameless image-guided stereotactic device that is becoming increasingly incorporated into the treatment of refractory pituitary tumors. A retrospective study indicated that $57.1 \%$ of patients with persistent or recurrent $\mathrm{CD}$ achieved biochemical remission after treatment with $\mathrm{CK}$, and few complications were observed (25). FSRT is also frequently employed for the treatment of residual or recurrent PAs. Minniti et al. analyzed the effects of FSRT in sixty-eight patients with large residual or recurrent NFPAs and found that the 5- and 10year actuarial local control rates were 97 and $91 \%$, respectively. However, the incidence of new hypopituitarism was $40 \%$ at 5 years and $72 \%$ at 10 years (26). Another study by Sheehan and colleagues indicated that GKRS treatment of patients with $\mathrm{CD}$ after failed TSS could result in $63 \%$ of the patients achieving normal 24-h urinary free cortisol (UFC) levels; however, $16 \%$ of the patients obtained new endocrine deficiencies (27). Losa et al. (28) conducted another retrospective analysis of patients with pituitary adenoma treated by GKRS and found that patients with NFPAs have more frequent recurrence of disease than patients with hormone-secreting adenomas (9.6 vs. $4.8 \%$ ). The 10 -year progression-free survival in patients with NFPAs was $78.7 \%$, which is much lower than that in patients in hormone-secreting adenomas (93.3\%). The data on re-irradiation for recurrent PAs are limited. To evaluate the safety and efficacy of re-irradiation for recurrent PAs, Verma et al. (29) retrospectively analyzed the outcomes of 15 patients receiving re-irradiation including fractionated RT and SRS. The results indicated that actuarial local control rates at 2 and 5 years were 80 and 58\%, respectively. However, the 5-year rate of radiation-induced optic neuropathy was $9 \%$, the 5 -year rate of temporal lobe necrosis was $28 \%$, and four patients $(27 \%)$ ultimately developed pituitary carcinoma after re-irradiation.

To compare the efficacy and safety of SRS and FSRT for treatment of PAs, X. Li performed a meta-analysis and founded that no significant differences were found in efficacy measures, such as disease control rate and endocrine cure rate, or complications, such as hypopituitarism and visual disturbance rate between SRS and FSRT. Therefore, both SRS and FSRT are comparable efficacious and safe for patients with Pas (30).

According to the Clinical Practice Guidelines initiated by European Society of Endocrinology (31), SRS is suited for the tumor $<3 \mathrm{~cm}$ in diameter and the tumor should be at least $3-5 \mathrm{~mm}$ distant from the optic chiasm. Otherwise, fractionated EBRT may be the only option. Furthermore, to avoid high dose radiation of healthy tissue, EBRT also should be preferred for tumors with irregular anatomy, including suprasellar or brainstem extension and diffuse local infiltration. Refractory PAs are not candidates for stereotactic RT because of tumor size $(>3 \mathrm{~cm})$ or tumor location near the optic apparatus and brainstem $(<5 \mathrm{~mm})$ (32). Risks associated with RT including hypopituitarism, optic neuropathy and other cranial neuropathies should be considered and avoided.

To conclude, both conventional EBRT and SRS have shown a good tumoristatic effect on residual or recurrent pituitary adenomas. In any of its modalities, RT constitutes a relatively cheap option for the treatment of these residual tumors.

\section{Medical Therapy}

Medical therapy plays an increasingly important role in the treatment of PAs. In secreting pituitary tumors, medications not only inhibit pituitary tumor growth but also control biochemical oversecretion in some cases. In recent years, there is accumulating evidence indicated that many medications used for functional tumors may be beneficial for residual or recurrent NFPAs.

\section{PRL-omas}

For patients with PRL-omas, DAs such as bromocriptine or cabergoline are the primary treatment and achieve successful treatment of these adenomas (33).

Cabergoline was more effective than bromocriptine in normalizing serum prolactin levels, shrinking prolactinomas, and controlling symptoms associated with hormone excess (34). E. Espinosa reported that Cabergoline treatment could result in the normalization of PRL levels in $68 \%$ and in the reduction of $50 \%$ in tumor volume in $87 \%$ of the giant PRL-oma patients (35). 
In most of PRL-omas, treatment with DAs, normalization of prolactin and tumor shrinkage could be achieved and do not require other surgical or radiotherapy interventions. However, a subset of patients with PRL-omas will resistant to dopamine agonists. Although there is no clear consensus on the definition of Resistant prolactinomas. Resistant prolactinomas is generally defined as a failure to normalize prolactin levels or inability to induce tumor shrinkage despite the administration of more than $15 \mathrm{mg}$ of bromocriptine daily for at least 3 months, or more than 1.5-2.0 mg of cabergoline weekly (36). There are several possible mechanisms of dopamine agonist resistance in prolactinomas. Most focus on decreased dopamine receptor expression, and alterations in cellular signaling factors downstream of dopamine receptors. The previous study had shown that resistance to dopaminergic agonists seems to involve defects in D2 dopamine receptor expression (37). Caccavelli et al. (38) furthermore found that decrease in D2 dopamine receptors is associated with a decrease in $G$ alpha i2 expression, and indicated that the resistance to dopaminergic agonists is not just due to decreased cell surface D2 receptors, but is also caused by decreased expression of the downstream of the D2 receptor ( $G$ alpha i2 inhibitory G protein). Shimazu et al. (39) also had proved that the reduction in D2L isoform mRNA levels is correlated with resistance of prolactinoma to dopamine agonists. PRDM2 is a retinoblastoma interacting zinc-finger protein, Gao et al. (40) had shown that PRDM2 downregulation may play a role in dopamine-agonist resistance.

There are a few therapeutic alternatives for DA-resistant prolactinomas, E. Sosa-Eroza reported that addition of octreotide to ongoing cabergoline treatment resulted in significant reductions in PRL levels and tumor volume in 2 out of 5 patients (41). Moreover, DAs treatment does also have some side effects, such as nausea, vomiting, headache, and dizziness or vertigo. Rapid tumor shrinkage caused by DAs could result in leakage of cerebrospinal fluid (CSF), which is a risk of DAs as well.

\section{Growth Hormone-Secreting PAs (GH-omas)}

TSS is recommended as the primary option for GH-omas; however, biochemical control could be achieved for only 40$60 \%$ of invasive $\mathrm{GH}$-omas, even with TSS performed by expert pituitary neurosurgeons (42). For those patients for whom surgical approaches have failed to control the disease, somatostatin analogs (SSAs), such as octreotide and lanreotide. are the next step option. The long-acting formulation of pasireotide has greater efficacy than octreotide and lanreotide and could be tried if octreotide and lanreotide are not effective (43). The SSAs could achieve biochemical control in only $20-35 \%$ of patients with GH-omas (44). Resistance to SSAs may be defined as a failure to achieve biochemical control criteria $(\mathrm{GH}<1.0 \mu \mathrm{g} / \mathrm{L}$ and a normal age-adjusted IGF-1) and increase in tumor size or tumor shrinkage $<20 \%$ compared with baseline volume after at least 12 months of treatment with SSAs (45).

Several markers have been shown to predict responsiveness to SRLs in acromegaly. These main predictors include somatostatin receptor (SSTR) expression, densely or scarcely granulated tumors, AIP and Ki-67 (46). It has been shown that resistance to SRLs is related to reduction of somatostatin receptor (SSTR) density or to a differentiated expression of SSTR subtypes (47). It is widely suggested that the response to SRLs treatment in acromegaly correlates with expression of the SSTR2 and SSTR5 subtypes (48-50). Besides SSTRs expression, AIP (aryl hydrocarbon receptor-interacting protein) also have been demonstrated to be associated with response to SRLs treatment. The previous studies indicated that low AIP expression in sporadic correlate to a poor response to SRLs $(51,52)$. Moreover, densely granulated GH-omas are highly responsive to SRLs than the sparsely granulated adenomas (53). Furthermore, Ki-67 also has been reported as a predictor of response to SRLs in GH-omas, which is independent of SSTR2 expression and relates to cytokeratin patterns (54). Therefore, personalized therapy based on these predictors could increase treatment efficacy with more rapid disease control and cost reduction.

Cabergoline also exhibited a therapeutic effect on GH-omas and could achieve biochemical control in approximately onethird of these patients; combining cabergoline with SSAs can further improve therapeutic success in $52 \%$ of patients with GH-omas (55). The most common adverse effects of SSAs are worsening of glucose tolerance and diabetes, gallbladder stones and sludge, abdominal cramps, flatulence, and diarrhea. Pegvisomant is a GH receptor antagonist that can decrease IGF1 levels in patients with $\mathrm{GH}$-oma. Although pegvisomant could normalize IGF-1 levels in $60-80 \%$ of patients, it cannot decrease $\mathrm{GH}$ levels or shrink tumor size because it does not have any direct effect on the tumors $(56,57)$. Surgical debulking of pituitary tumors, radiotherapy and radiosurgery are reserved for patients who are resistant or intolerant to medical treatment.

\section{Adrenocorticotropin Hormone (ACTH)-Secreting PAs}

As the initial preferred treatment, TSS could achieve a high (70-85\%) rate of remission in ACTH-secreting PAs; however, tumors may recur in up to $25 \%$ of patients and require further therapy (58). If surgery fails, then options including medical therapy, pituitary irradiation, or bilateral adrenalectomy are used. Several medications have been reported to normalize cortisol levels and improve morbidity and mortality. Currently available medical treatments for patients with ACTH-secreting PAs include steroidogenesis inhibitors, centrally acting agents, and a glucocorticoid receptor antagonist.

Pasireotide and cabergoline can directly act on ACTHsecreting PAs via inhibiting ACTH production. As a novel multireceptor ligand SSA with a high binding affinity for somatostatin (SST) receptors, pasireotide could act directly on ACTH-secreting PAs to inhibit ACTH production. Pasireotide can normalize cortisol levels in $19 \%$ of patients with CD. However, pasireotide also caused a worsening of glucose tolerance in $73 \%$ of these patients (59). Cabergoline is a newer dopamine agonist and has high affinity for the dopamine receptor subtype 2, which is expressed in most ACTH-secreting PAs. 
Recent studies showed that cabergoline can normalize cortisol levels in approximately one-third of patients with CD (60).

Steroidogenesis inhibitors currently in use include ketoconazole, metyrapone, mitotane, and etomidate (61). Although ketoconazole could normalize cortisol levels in approximately $50 \%$ of patients with ACTH-secreting PAs, $20.5 \%$ of them could not continue the treatment due to poor tolerance including liver toxicity and gastrointestinal complaints (62).

Metyrapone, a steroidogenesis inhibitor, could convert 11deoxycortisol to cortisol and control cortisol levels in 50-76\% of patients with CD. However, metyrapone use also results in adverse events including mild gastrointestinal upset and dizziness in $25 \%$ of patients (63). Mitotane is an adrenolytic agent used in the treatment of adrenocortical carcinoma, and it has recently been approved for the treatment of CD. Long-term treatment with mitotane can cause remission in $72 \%$ of patients with $\mathrm{CD}$, but gastrointestinal and neurologic side effects are very common (64). If all the above measures fail, the intravenous imidazole derivative etomidate could be useful. Etomidate can block several steps in cortisol synthesis and may be used as firstline treatment for severe hypercortisolism in patients with severe CD (65). Recent guidelines suggest that etomidate may be useful for patients with life-threatening hypercortisolemia who cannot take oral medications (66).

Mifepristone is a glucocorticoid receptor antagonist and antiprogestin. Mifepristone does not inhibit cortisol synthesis but directly antagonizes its effects via blocking the cortisol glucocorticoid receptor and the progesterone receptor. Mifepristone is useful for the control of diabetes or glucose intolerance caused by hypercortisolism. Mifepristone could improve diabetes and hypertension in 60 and $40 \%$ of patients with Cushing's syndrome, respectively, and $87 \%$ of these patients showed significant clinical and quality-of-life improvements (67). However, ACTH levels increased dramatically in $72 \%$ of patients, and cortisol levels remained unchanged or increased during treatment. The common side effects of mifepristone were cortisol insufficiency symptoms including fatigue, nausea, headache, low potassium, arthralgia, vomiting and edema (67). Combinations of some of these medications may be more effective than single agents in some patients; however, the adverse events should be considered as well.

Osilodrostat, a potent oral 11b-hydroxylase inhibitor, has been proved that could normalize urinary free cortisol (UFC) in patients with $\mathrm{CD}$. The result from a Phase II clinical trial indicated that Osilodrostat treatment reduced UFC in all CD patients; $78.9 \%(\mathrm{n} / \mathrm{N}=15 / 19)$ had normal UFC at week 22 (68). Roscuvitine is a CDK2 inhibitor, Liu et al. have proved that roscuvitine could inhibit human pituitary corticotroph tumor ACTH by targeting the cyclinE/E2F1 pathway (69). Liu et al. (69) demonstrated that USP8.STAM complex as a protective mechanism regulating early endosomal sorting of EGFR between pathways destined for lysosomal degradation and recycling.

The previous studies have shown retinoic acid could inhibits ACTH secretion in vitro by inhibiting the transcriptional activity (70). Pecori Giraldi et al. (71) evaluated the efficacy and safety profile of retinoic acid in patients with $\mathrm{CD}$, and found that retinoic acid proved beneficial and well tolerated in $71 \%$ of $(5 / 7)$ patients with CD. Vilar et al. (72) also proved that combination of isotretinoin (13-cis-retinoic acid) with cabergoline may occasionally be more effective than either drug alone.

Although medical treatment in ACTH-secreting PAs has achieved rapid advancement, some refractory $\mathrm{CD}$ cases are still resistant to current medications, and bilateral adrenalectomy would be required (72). Adrenalectomy could achieve immediate cessation of hypercortisolism but will result in life-long adrenal insufficiency and Nelson syndrome (73).

\section{NFPAs}

Because of the lack of clinical symptoms caused by secreted hormones, most NFPAs are large at diagnosis due to symptoms related to mass effect. Complete resection is not always possible, especially in large invasive macroadenomas. Adjuvant radiation can effectively prevent residual tumor growth, but re-growth or recurrence often occur; therefore, effective medical treatment for NFPA is necessary.

DAs are the first-line choice of treatment of PRL-omas via the activity of dopamine receptors. Most NFPAs also express dopamine receptor 2 (D2R), which may be a potential therapeutic target for NFPAs (74). Previous studies have suggested that DAs are effective in the treatment of NFPAs. Greenman et al. (75) evaluated the effect of DAs on postsurgical NFPAs; their results showed that after preventive treatment with DAs, $38 \%$ of patients achieved a decrease, $49 \%$ showed no change, and $13 \%$ showed an increase in tumor size,. Further, DAs induced tumor shrinkage or restrained tumor growth in over $58 \%$ of patients who already have tumor enlargement.

SST receptor ligands are widely used for medical treatment of acromegaly and thyroid-stimulating hormone (TSH)-secreting tumors. SST inhibits tumor cell growth arrest and hormone secretion through binding of five different SST receptors.

NFPAs express different SST receptors as well, suggesting that SST receptor ligands may be an effective medical treatment for NFPAs (76). Colao et al. (77) summarized case reports and small uncontrolled studies and found that in patients treated with octreotide, tumor volume was decreased in $12 \%$, increased in only $5 \%$ and remained unchanged in $83 \%$ of these patients. In a case-control study conducted by Fusco et al., 26 preselected patients with positive tumor uptake in SST receptor scintigraphy were treated with the long-acting SST LAR; tumor size increased in $19 \%$ of the patients, and the remaining patients remained stable (78).

\section{FUTURE PERSPECTIVES AND CONCLUSIONS}

Temozolomide (TMZ) is an orally administered alkylating chemotherapy that readily crosses the blood-brain barrier. TMZ is considered the standard treatment in the management of gliomas. In 2006, the first successful treatment of PA 
with TMZ was reported $(79,80)$, and TMZ treatment has also been widely used for patients with refractory PAs and carcinomas (81). In 2017, the European Society of Endocrinology Clinical Practice Guidelines recommended the use of TMZ monotherapy as first-line chemotherapy for aggressive PAs and pituitary carcinomas (31). To our knowledge and to date, approximately 160 cases of pituitary tumors treated with TMZ have been reported. The data form a Multicenter retrospective study indicated a 51.2\% response rate to TMZ, with an improved survival among responders despite frequent relapses (82). In a recent meta-analysis, the 5 -year OS and 5-year progression free survival for aggressive pituitary adenomas treated with TMZ was 57.4 and $21.9 \%$ respectively (83).

However, most of refractory PAs failed to respond to TMZ and even acquired TMZ resistance after an effective response to TMZ (82). Therefore, it is important to enhance the efficacy of TMZ and overcome the resistance to TMZ. The presence of certain molecules in pituitary tumors, such as MGMT and MSH6, has been associated with temozolomide response (84).

Epidermal growth factor is a cell growth factor that regulates cell proliferation and hormone production in pituitary tumors (85). EGFR is overexpressed in prolactinoma and ACTH-secreting PAs, which may offer a potential therapeutic target for refractory pituitary tumors $(86,87)$. As an EGFR inhibitor, gefitinib has shown antiproliferative and apoptotic effects in corticotroph tumor cells in vitro (86). Lapatinib, a dual HER2/EGFR inhibitor, was shown to suppress both the expression and secretion of PRL mRNA to a greater extent than gefitinib in an animal model of prolactinoma (88). Although further clinical trials are needed, preclinical data suggest that the EGFR pathway may be an effective therapeutic target for patients with refractory pituitary tumors.

Vascular endothelial growth factor (VEGF) is a potent angiogenic factor in pituitary tumors. Previous studies have indicated that angiogenesis is associated with adenoma development, local invasion, and recurrence (89-91). Several studies reported that angiogenesis decreases tumor sizes in humans and experimental pituitary tumors (89, 92, 93). Ortiz et al. reported the first case of a bevacizumab-treated pituitary carcinoma with long-term stabilization of disease in 2012 (94). Touma et al. also presented one case of pituitary carcinoma treated successfully with concurrent chemoradiation therapy and bevacizumab with long-term follow-up (95). However, the role of anti-VEGF therapy in pituitary tumors is still controversial due to a lack of large-scale clinical trials.

$\mathrm{PI} 3 \mathrm{~K} / \mathrm{AKT} / \mathrm{mTOR}$ cascades are key signaling pathways in the tumorigenesis of PA (96). Previous studies reported that the $\mathrm{PI} 3 \mathrm{~K} / \mathrm{AKT} / \mathrm{mTOR}$ pathway is upregulated and overactivated in PAs, indicating an important role in tumor formation and progression of PAs (97-99). Inhibition of the PI3K/mTOR signaling pathway not only displays antitumor efficacy against pituitary tumors $(100,101)$ but also sensitizes PA cells to radiotherapy and chemotherapy $(102,103)$. Donovan et al. reported one patient with pituitary carcinoma, which is refractory to multiple surgery, radiation and chemotherapy, who achieved clinical improvement and stability for more than 6 months after treatment with an mTOR inhibitor and radiation (104).

As a promising therapeutic approach, cancer immunotherapy has been attracting increasing attention recently. To date, immunotherapy has been used for the treatment of many tumors, including glioma, lung cancer, melanoma, prostate cancer, and B cell lymphoma (105). In 2007, Hazrati et al. reported one case of a prolactinoma treated successfully with immunotherapy for the first time (106). Lu et al. have reported that CD68+ macrophage infiltration is associated with PA size and invasiveness, indicating that immunotherapy may be useful to restrict the tumor enlargement and invasiveness (107). Blocking the interaction between the programmed cell death (PD-1) protein and one of its ligands, programmed death ligand 1 (PD-L1), is a novel strategy for cancer immunotherapy. The expression of PD-L1 is positively correlated with improved responses to anti-PD-1/PD-L1 blockade in many cancers (108). Mei et al. reported that the expression of PD-L1 is significantly higher in human functioning adenomas compared to that in nonfunctioning adenomas, suggesting the existence of an immune response to pituitary tumors (109). Therefore, these studies raise the possibility of considering immunotherapy for refractory PAs.

\section{CONCLUSION}

In summary, refractory pituitary tumors are usually unresponsive to different therapies and have a poor prognosis. To improve the survival of patients, early identification and a multidisciplinary approach is required. Although various treatment options are available to manage these refractory pituitary tumors, the efficacy is limited. Therefore, new therapeutic approaches and randomized clinical trials are needed. It is hoped that further research may clarify the tumorigenesis and pathogenesis of refractory pituitary tumors and that additional alternative treatments may be developed for these tumors.

\section{AUTHOR CONTRIBUTIONS}

All authors listed have made a substantial, direct and intellectual contribution to the work, and approved it for publication.

\section{FUNDING}

This work was supported by the National Natural Science Foundation of China (Grant 81502639 and 81372414). The funding institution had no role in study design, data collection and analysis, decision to publish, or preparation of the manuscript. 


\section{REFERENCES}

1. Colao A, Grasso LF, Pivonello R, Lombardi G. Therapy of aggressive pituitary tumors. Expert Opin Pharmaco. (2011) 12:1561-70. doi: $10.1517 / 14656566.2011 .568478$

2. Scheithauer BW, Kovacs KT, Laws JER, Randall RV. Pathology of invasive pituitary tumors with special reference to functional classification. J Neurosurg. (1986) 65:733. doi: 10.3171/jns.1986.65.6.0733

3. Dai C, Feng M, Liu X, Ma S, Sun B, Bao X, et al. Refractory pituitary adenoma: a novel classification for pituitary tumors. Oncotarget. (2016) 7:83657-68. doi: 10.18632 /oncotarget.13274

4. Trouillas J, Roy P, Sturm N, Dantony E, Cortet-Rudelli C, Viennet $\mathrm{G}$, et al. A new prognostic clinicopathological classification of pituitary adenomas: a multicentric case-control study of 410 patients with 8 years post-operative follow-up. Acta Neuropathol. (2013) 126:123-35. doi: 10.1007/s00401-013-1084-y

5. Chatzellis E, Alexandraki KI, Androulakis II, Kaltsas G. Aggressive pituitary tumors. Neuroendocrinology. (2015) 101:87-104. doi: 10.1159/000371806

6. Heaney A. Management of aggressive pituitary adenomas and pituitary carcinomas. J Neuro Oncol. (2014) 117:459-68. doi: $10.1007 /$ s11060-014-1413-6

7. Primeau V, Raftopoulos C, Maiter D. Outcomes of transsphenoidal surgery in prolactinomas: improvement of hormonal control in dopamine agonist-resistant patients. Eur J Endocrinol. (2012) 166:779-86. doi: 10.1530/EJE-11-1000

8. Jane JJ, Laws EJ. The surgical management of pituitary adenomas in a series of 3,093 patients. J Am Coll Surg. (2001) 193:651-9. doi: 10.1016/S1072-7515(01)01101-2

9. Vargas G, Gonzalez B, Ramirez C, Ferreira A, Espinosa E, Mendoza V, et al. Clinical characteristics and treatment outcome of 485 patients with nonfunctioning pituitary macroadenomas. Int J Endocrinol. (2015) 2015:1-7. doi: $10.1155 / 2015 / 756069$

10. Sheehan J, Lee CC, Bodach ME, Tumialan LM, Oyesiku NM, Patil CG, et al. Congress of neurological surgeons systematic review and evidencebased guideline for the management of patients with residual or recurrent nonfunctioning pituitary adenomas. Neurosurgery. (2016) 79:E539-40. doi: 10.1227/NEU.0000000000001385

11. Mercado M, Melgar V, Salame L, Cuenca D. Clinically nonfunctioning pituitary adenomas: pathogenic, diagnostic and therapeutic aspects. Endocrinol Diabetes Nutr. (2017) 64:384-95. doi: 10.1016/j.endien.2017.08.012

12. Espinosa De Los Monteros A, González B, Vargas G, Sosa E, Guinto G, Mercado M. Surgical reintervention in acromegaly: is it still worth trying? Endocr Pract. (2009) 15:431-7. doi: 10.4158/EP09066.ORR

13. Almeida JP, Ruiz-Trevino AS, Liang B, Omay SB, Shetty SR, Chen YN, et al. Reoperation for growth hormone-secreting pituitary adenomas: report on an endonasal endoscopic series with a systematic review and meta-analysis of the literature. J Neurosurg. (2018) 129:404-16. doi: 10.3171/2017.2.JNS162673

14. Espinosa-de-los-Monteros AL, Sosa-Eroza E, Espinosa E, Mendoza V, Arreola R, and Mercado M. Long-term outcome of the different treatment alternatives for recurrent and persistent cushing disease. Endocr Pract. (2017) 23:759-67. doi: 10.4158/EP171756.OR

15. Rutkowski MJ, Flanigan PM, Aghi MK. Update on the management of recurrent Cushing's disease. Neurosurg Focus. (2015) 38:E16. doi: 10.3171/2014.11.FOCUS14703

16. Heringer LC, de Oliveira MF, Rotta JM, Botelho RV. Effect of repeated transsphenoidal surgery in recurrent or residual pituitary adenomas: a systematic review and meta-analysis. Surg Neurol Int. (2016) 7:14. doi: $10.4103 / 2152-7806.175896$

17. Esquenazi Y, Essayed WI, Singh H, Mauer E, Ahmed M, Christos PJ, et al. Endoscopic endonasal versus microscopic transsphenoidal surgery for recurrent and/or residual pituitary adenomas. World Neurosurg. (2017) 101:186-95. doi: 10.1016/j.wneu.2017.01.110

18. Do H, Kshettry VR, Siu A, Belinsky I, Farrell CJ, Nyquist G, et al. Extent of resection, visual, and endocrinologic outcomes for endoscopic endonasal surgery for recurrent pituitary adenomas. World Neurosurg. (2017) 102:35-41. doi: 10.1016/j.wneu.2017.02.131
19. Li A, Liu W, Cao P, Zheng Y, Bu Z, Zhou T. Endoscopic versus microscopic transsphenoidal surgery in the treatment of pituitary adenoma: a systematic review and meta-analysis. World Neurosurg. (2017) 101:236-46. doi: 10.1016/j.wneu.2017.01.022

20. Minniti G, Flickinger J, Tolu B, Paolini S. Management of nonfunctioning pituitary tumors: radiotherapy. Pituitary. (2018) 21:154-61. doi: 10.1007/s11102-018-0868-4

21. Lee C, Sheehan JP. Advances in Gamma Knife radiosurgery for pituitary tumors. Curr Opin Endocrinol Diabetes Obes. (2016) 23:331-8. doi: 10.1097/MED.0000000000000269

22. Kong D, Lee J, Lim DH, Kim KW, Shin HJ, Nam D, et al. The efficacy of fractionated radiotherapy and stereotactic radiosurgery for pituitary adenomas. Cancer Am Cancer Soc. (2007) 110:854-60. doi: $10.1002 /$ cncr.22860

23. Mehta GU, Ding D, Patibandla MR, Kano H, Sisterson N, Su Y, et al. Stereotactic radiosurgery for cushing disease: results of an international, multicenter study. J. Clin. Endocrinol. Metabol. (2017) 102:4284-91. doi: 10.1210/jc.2017-01385

24. Cohen-Inbar O, Ramesh A, Xu Z, Vance ML, Schlesinger D, Sheehan JP. Gamma knife radiosurgery in patients with persistent acromegaly or Cushing's disease: long-term risk of hypopituitarism. Clin Endocrinol. (2016) 84:524-31. doi: $10.1111 /$ cen.12938

25. Moore JM, Sala E, Amorin, A. Jr., Martinez H, Bhowmik AC, Chang SD, Soltys SG, et al. CyberKnife radiosurgery in the multimodal management of patients with cushing's disease. World Neurosurg. (2018) 112:e425-30. doi: 10.1016/j.wneu.2018.01.057

26. Minniti G, Scaringi C, Poggi M, Jaffrain Rea ML, Trillo G, Esposito V, et al. Fractionated stereotactic radiotherapy for large and invasive non functioning pituitary adenomas: long-term clinical outcomes and volumetric MRI assessment of tumor response. Eur J Endocrinol. (2015) 172:433-41. doi: 10.1530/EJE-14-0872

27. Sheehan JM, Vance ML, Sheehan JP, Ellegala DB, Laws EJ. Radiosurgery for Cushing's disease after failed transsphenoidal surgery. J Neurosurg. (2000) 93:738-42. doi: 10.3171/jns.2000.93.5.0738

28. Losa M, Spatola G, Albano L, Gandolfi A, Del Vecchio A, Bolognesi $\mathrm{A}$, et al. Frequency, pattern, and outcome of recurrences after gamma knife radiosurgery for pituitary adenomas. Endocrine. (2017) 56:595-602. doi: 10.1007/s12020-016-1081-8

29. Verma J, McCutcheon IE, Waguespack SG, Mahajan A. Feasibility and outcome of re-irradiation in the treatment of multiply recurrent pituitary adenomas. Pituitary. (2014) 17:539-45. doi: 10.1007/s11102-013$0541-x$

30. Li X, Li Y, Cao Y, Li P, Liang B, Sun J, et al. Safety and efficacy of fractionated stereotactic radiotherapy and stereotactic radiosurgery for treatment of pituitary adenomas: a systematic review and meta-analysis. J Neurol Sci. (2017) 372:110-6. doi: 10.1016/j.jns.2016.11.024

31. Raverot G, Burman P, McCormack A, Heaney A, Petersenn S, Popovic $\mathrm{V}$, et al. European society of endocrinology clinical practice guidelines for the management of aggressive pituitary tumours and carcinomas. Eur $J$ Endocrinol. (2017) 178:G1-24. doi: 10.1530/E. J. E.-17-0796

32. Buchfelder M. Management of aggressive pituitary adenomas: current treatment strategies. Pituitary. (2009) 12:256-60. doi: 10.1007/s11102-0080153-z

33. Olafsdottir A, Schlechte J. Management of resistant prolactinomas. Nat Clin Prac Endocrinol Metabol. (2006) 2:552-61. doi: 10.1038/ncpendmet0290

34. Arduc A, Gokay F, Isik S, Ozuguz U, Akbaba G, Tutuncu Y, et al. Retrospective comparison of cabergoline and bromocriptine effects in hyperprolactinemia: a single center experience. J Endocrinol Invest. (2015) 38:447-53. doi: 10.1007/s40618-014-0212-4

35. Espinosa E, Sosa E, Mendoza V, Ramírez C, Melgar V, Mercado M. Giant prolactinomas: are they really different from ordinary macroprolactinomas? Endocrine. (2016) 52:652-9. doi: 10.1007/s12020-015-0791-7

36. Oh MC, Aghi MK. Dopamine agonist-resistant prolactinomas. J Neurosurg. (2011) 114:1369-79. doi: 10.3171/2010.11.JNS101369

37. Caccavelli L, Feron F, Morange I, Rouer E, Benarous R, Dewailly $\mathrm{D}$, et al. Decreased expression of the two D2 dopamine receptor isoforms in bromocriptine-resistant prolactinomas. Neuroendocrinology. (1994) 60:314-22. doi: 10.1159/000126764 
38. Caccavelli L, Morange-Ramos I, Kordon C, Jaquet P, Enjalbert A. Alteration of $\mathrm{G}$ alpha subunits $\mathrm{mRNA}$ levels in bromocriptine resistant prolactinomas. J Neuroendocrinol. (1996) 8:737-46. doi: 10.1046/j.1365-2826.1996.04902.x

39. Shimazu S, Shimatsu A, Yamada S, Inoshita N, Nagamura Y, Usui T, et al. Resistance to dopamine agonists in prolactinoma is correlated with reduction of dopamine D2 receptor long isoform mRNA levels. Eur J Endocrinol. (2012) 166:383-90. doi: 10.1530/EJE-11-0656

40. Gao H, Wang F, Lan X, Li C, Feng J, Bai J, et al. Lower PRDM2 expression is associated with dopamine-agonist resistance and tumor recurrence in prolactinomas. BMC Cancer. (2015) 15:272-82. doi: 10.1186/s12885-015-1267-0

41. Sosa-Eroza E, Espinosa E, Ramírez-Rentería C, Mendoza V, Arreola $\mathrm{R}$, Mercado M. Treatment of multiresistant prolactinomas with a combination of cabergoline and octreotide LAEndocrine R. (2018) 61:343-8. doi: $10.1007 / \mathrm{s} 12020-018-1638-9$

42. Abu DA, Mohammed K, Asi N, Farah WH, Wang Z, Farah MH, et al. Surgical interventions and medical treatments in treatment-naive patients with acromegaly: systematic review and meta-analysis. J Clin Endocrinol Metab. (2014) 99:4003-14. doi: 10.1210/jc.2014-2900

43. Gadelha MR, Bronstein MD, Brue T, Coculescu M, Fleseriu M, Guitelman $\mathrm{M}$, et al. Pasireotide versus continued treatment with octreotide or lanreotide in patients with inadequately controlled acromegaly (PAOLA): a randomised, phase 3 trial. Lancet Diabetes Endocrinol. (2014) 2:875-84.doi: 10.1016/S2213-8587(14)70169-X

44. Manjila S, Wu OC, Khan FR, Khan MM, Arafah BM, Selman WR. Pharmacological management of acromegaly: a current perspective. Neurosurg Focus. (2010) 29:E14. doi: 10.3171/2010.7.FOCUS10168

45. Colao A, Auriemma RS, Lombardi G, Pivonello R. Resistance to somatostatin analogs in acromegaly. Endocr Rev. (2011) 32:247-71. doi: 10.1210/er.2010-0002

46. Colao A, Grasso L, Giustina A, Melmed S, Chanson P, Pereira AM, et al. Acromegaly. Nat Rev Dis Primers. (2019) 5:20. doi: 10.1038/s41572-019-0071-6

47. Bronstein MD. Acromegaly: molecular expression of somatostatin receptor subtypes and treatment outcome. Front Horm Res. (2006) 35:129-34. doi: $10.1159 / 000094315$

48. Gadelha MR, Wildemberg LE, Bronstein MD, Gatto F, Ferone D. Somatostatin receptor ligands in the treatment of acromegaly. Pituitary. (2017) 20:100-8. doi: 10.1007/s11102-017-0791-0

49. Brzana J, Yedinak CG, Gultekin SH, Delashaw JB, Fleseriu M. Growth hormone granulation pattern and somatostatin receptor subtype $2 \mathrm{~A}$ correlate with postoperative somatostatin receptor ligand response in acromegaly: a large single center experience. Pituitary. (2013) 16:490-8. doi: 10.1007/s11102-012-0445-1

50. Muhammad A, Coopmans EC, Gatto F, Franck SE, Janssen, J. Pasireotide Responsiveness in acromegaly is mainly driven by somatostatin receptor subtype 2 expression. J Clin Endocrinol Metab. (2019) 104:915-24. doi: 10.1210/jc.2018-01524

51. Ozkaya HM, Comunoglu N, Sayitoglu M, Keskin FE, Firtina S, Khodzhaev K, et al. Germline mutations of aryl hydrocarbon receptorinteracting protein (AIP) gene and somatostatin receptor $1-5$ and AIP immunostaining in patients with sporadic acromegaly with poor versus good response to somatostatin analogues. Pituitary. (2018) 21:335-46. doi: 10.1007/s11102-018-0876-4

52. Kasuki L, Vieira NL, Wildemberg LE, Colli LM, de Castro M, Takiya CM, et al. AIP expression in sporadic somatotropinomas is a predictor of the response to octreotide LAR therapy independent of SSTR2 expression. Endocr Relat Cancer. (2012) 19:L25-9. doi: 10.1530/ERC-12-0020

53. Fougner SL, Casar-Borota O, Heck A, Berg JP, Bollerslev J. Adenoma granulation pattern correlates with clinical variables and effect of somatostatin analogue treatment in a large series of patients with acromegaly. Clin Endocrinol. (2012) 76:96-102. doi: $10.1111 /$ j.1365-2265.2011.04163.x

54. Kasuki L, Wildemberg LE, Neto LV, Marcondes J, Takiya CM, Gadelha MR. $\mathrm{Ki}-67$ is a predictor of acromegaly control with octreotide LAR independent of SSTR2 status and relates to cytokeratin pattern. Eur J Endocrinol. (2013) 169:217-23. doi: 10.1530/EJE-13-0349

55. Sandret L, Maison P, Chanson P. Place of cabergoline in acromegaly: a meta-analysis. J Clin Endocrinol Metab. (2011) 96:1327-35. doi: 10.1210/jc.2010-2443
56. van der Lely J, Jonsson P, Wilton P, Akerblad AC, Cara J, Ghigo E. Treatment with high doses of pegvisomant in 56 patients with acromegaly: experience from ACROSTUDY. Eur J Endocrinol. (2016) 175:239-45. doi: 10.1530/EJE-16-0008

57. Chanson P, Brue T, Delemer B, Caron P, Borson-Chazot F, Zouater H. Pegvisomant treatment in patients with acromegaly in clinical practice: The French ACROSTUD. Ann Endocrinol Y. (2015) 76:664-70. doi: 10.1016/j.ando.2015.10.003

58. Fleseriu M. Medical management of persistent and recurrent cushing disease. Neurosurg Clin N Am. (2012) 23:653-68. doi: 10.1016/j.nec.2012.06.012

59. Ceccato F, Scaroni C, Boscaro M. Clinical use of pasireotide for Cushing's disease in adults. Ther Clin Risk Manag. (2015) 11:425-34. doi: 10.2147/TCRM.S37314

60. Godbout A, Manavela M, Danilowicz K, Beauregard H, Bruno OD, Lacroix A. Cabergoline monotherapy in the long-term treatment of Cushing's disease. Eur J Endocrinol. (2010) 163:709-16. doi: 10.1530/EJE-10-0382

61. Bertagna X, Guignat L, Groussin L, Bertherat J. Cushing's disease. Best Pract Res Clin Endocrinol Metab. (2009) 23:607-23. doi: 10.1016/j.beem.2009.06.001

62. Castinetti F, Guignat L, Giraud P, Muller M, Kamenicky P, Drui D, et al. Ketoconazole in Cushing's disease: is it worth a try? J Clin Endocrinol Metab. (2014) 99:1623-30. doi: 10.1210/jc.2013-3628

63. Daniel E, Aylwin S, Mustafa O, Ball S, Munir A, Boelaert K, et al. Effectiveness of metyrapone in treating cushing's syndrome: a retrospective multicenter study in 195 patients. J Clin Endocrinol Metab. (2015) 100:4146-54. doi: 10.1210/jc.2015-2616

64. Baudry C, Coste J, Bou KR, Silvera S, Guignat L, Guibourdenche J, et al. Efficiency and tolerance of mitotane in Cushing's disease in 76 patients from a single center. Eur J Endocrinol. (2012) 167:473-81. doi: 10.1530/EJE-12-0358

65. Preda VA, Sen J, Karavitaki N, Grossman A. Etomidate in the management of hypercortisolaemia in cushing's syndrome. Eur Endocrinol J. (2012) 167:137-43. doi: 10.1530/EJE-12-0274

66. Nieman LK, Biller BMK, Findling JW, Murad MH, Newell-Price J, Savage MO, et al. Treatment of cushing's syndrome: an endocrine society clinical practice guideline. J Clin Endocrinol Metabol. (2015) 100:2807-31. doi: 10.1210/jc.2015-1818

67. Fleseriu M, Biller BMK, Findling JW, Molitch ME, Schteingart DE, Gross $\mathrm{C}$, et al. Mifepristone, a glucocorticoid receptor antagonist, produces clinical and metabolic benefits in patients with cushing's syndrome. J Clin Endocrinol Metabol. (2012) 97:2039-49. doi: 10.1210/jc.2011-3350

68. Fleseriu M, Pivonello R, Young J, Hamrahian AH, Molitch ME, Shimizu C, et al. Osilodrostat, a potent oral $11 \beta$-hydroxylase inhibitor: 22 -week, prospective, Phase II study in Cushing's disease. Pituitary. (2016) 19:138-48. doi: $10.1007 / \mathrm{s} 11102-015-0692-\mathrm{z}$

69. Liu N, Araki T, Cuevas-Ramos D, Hong J, Ben-Shlomo A, Tone Y, et al. Cyclin E-mediated human proopiomelanocortin regulation as a therapeutic target for cushing disease. J Clin Endocrinol Metabol. (2015) 100:2557-64. doi: 10.1210/jc.2015-1606

70. Paez-Pereda M, Kovalovsky D, Hopfner U, Theodoropoulou M, Pagotto U, Uhl E, et al. Retinoic acid prevents experimental Cushing syndrome. J Clin Invest. (2001) 108:1123-31. doi: 10.1172/JCI11098

71. Pecori Giraldi F, Ambrogio AG, Andrioli M, Sanguin F, Karamouzis I, Corsello SM, et al. Potential role for retinoic acid in patients with cushing's disease. J Clin Endocrinol Metabol. (2012) 97:3577-83. doi: 10.1210/jc.2012-2328

72. Vilar L, Albuquerque JL, Lyra R, Trovão Diniz E, Rangel Filho F, Gadelha P, et al. The role of isotretinoin therapy for cushing's disease: results of a prospective study. Int J Endocrinol. (2016) 2016:1-9. doi: $10.1155 / 2016 / 8173182$

73. Guerin C, Taieb D, Treglia G, Brue T, Lacroix A, Sebag F, et al. Bilateral adrenalectomy in the 21st century: when to use it for hypercortisolism? Endocr Relat Cancer. (2015) 23:R131-42. doi: 10.1530/ERC15-0541

74. Vieira Neto L, Wildemberg LE, Moraes AB, Colli LM, Kasuki L, Marques $\mathrm{NV}$, et al. Dopamine receptor subtype 2 expression profile in nonfunctioning pituitary adenomas andin vivo response to cabergoline therapy. Clin Endocrinol. (2015) 82:739-46. doi: 10.1111/cen.12684

75. Greenman Y, Cooper O, Yaish I, Robenshtok E, Sagiv N, JonasKimchi T, et al. Treatment of clinically nonfunctioning pituitary 
adenomas with dopamine agonists. Eur J Endocrinol. (2016) 175:63-72. doi: 10.1530/EJE-16-0206

76. Lee M, Lupp A, Mendoza N, Martin N, Beschorner R, Honegger J, et al. SSTR3 is a putative target for the medical treatment of gonadotroph adenomas of the pituitary. Endocr Relat Cancer. (2015) 22:111-9. doi: 10.1530/ERC-14-0472

77. Colao A, Di Somma C, Pivonello R, Faggiano A, Lombardi G, Savastano S. Medical therapy for clinically non-functioning pituitary adenomas. Endocrine Related Cancer. (2008) 15:905-15. doi: 10.1677/ERC-08-0181

78. Fusco A, Giampietro A, Bianchi A, Cimino V, Lugli F, Piacentini S, et al. Treatment with octreotide LAR in clinically non-functioning pituitary adenoma: results from a case-control study. Pituitary. (2012) 15:571-8. doi: 10.1007/s11102-011-0370-8

79. Fadul CE, Kominsky AL, Meyer LP, Kingman LS, Kinlaw WB, Rhodes CH, et al. Long-term response of pituitary carcinoma to temozolomide. Report of two cases. J Neurosurg. (2006) 105:621-6. doi: 10.3171/jns.2006.105.4.621

80. Lim S, Shahinian H, Maya MM, Yong W, Heaney AP. Temozolomide: a novel treatment for pituitary carcinoma. Lancet Oncol. (2006) 7:518-20. doi: 10.1016/S1470-2045(06)70728-8

81. Losa M, Bogazzi F, Cannavo S, Ceccato F, Curt L, De Marinis L, et al. Temozolomide therapy in patients with aggressive pituitary adenomas or carcinomas. J Neuro Oncol. (2016) 126:519-25. doi: 10.1007/s11060-015-1991-y

82. Lasolle H, Cortet C, Castinetti F, Cloix L, Caron P, Delemer B, et al. Temozolomide treatment can improve overall survival in aggressive pituitary tumors and pituitary carcinomas. Eur J Endocrinol. (2017) 176:76977. doi: 10.1530/EJE-16-0979

83. Ji Y, Vogel RI, Lou E. Temozolomide treatment of pituitary carcinomas and atypical adenomas: systematic review of case reports. Neurooncol Pract. (2016) 3:188-95. doi: 10.1093/nop/npv059

84. Matsuno A, Murakami M, Hoya K, Yamada SM, Miyamoto S, Yamada S, et al. Molecular status of pituitary carcinoma and atypical adenoma that contributes the effectiveness of temozolomide. Med Mol Morphol. (2014) 47:1-7. doi: 10.1007/s00795-013-0050-z

85. Cooper O, Mamelak A, Bannykh S, Carmichael J, Bonert V, Lim S, et al. Prolactinoma ErbB receptor expression and targeted therapy for aggressive tumors. Endocrine. (2014) 46:318-27. doi: 10.1007/s12020-013-0093-x

86. Fukuoka H, Cooper O, Ben-Shlomo A, Mamelak A, Ren S, Bruyette D, et al. EGFR as a therapeutic target for human, canine, and mouse ACTH-secreting pituitary adenomas. J Clin Invest. (2011) 121:4712-21. doi: 10.1172/JCI60417

87. Fukuoka H, Cooper O, Mizutani J, Tong Y, Ren SG, Bannykh S, et al. HER2/ErbB2 receptor signaling in rat and human prolactinoma cells: strategy for targeted prolactinoma therapy. Mol Endocrinol. (2011) 25:92-103. doi: 10.1210/me.2010-0353

88. Liu X, Kano M, Araki T, Cooper O, Fukuoka H, Tone Y, et al. ErbB receptordriven prolactinomas respond to targeted lapatinib treatment in female transgenic mice. Endocrinology. (2015) 156:71-9. doi: 10.1210/en.2014-1627

89. Cristina C, Luque GM, Demarchi G, Lopez Vicchi F, Zubeldia-Brenner L, Perez Millan MI, et al. Angiogenesis in pituitary adenomas: human studies and new mutant mouse models. Int J Endocrinol. (2014) 2014:1-11. doi: $10.1155 / 2014 / 608497$

90. Sánchez-Ortiga R, Sánchez-Tejada L, Moreno-Perez O, Riesgo P, Niveiro M, Picó Alfonso AM. Over-expression of vascular endothelial growth factor in pituitary adenomas is associated with extrasellar growth and recurrence. Pituitary. (2013) 16:370-7. doi: 10.1007/s11102-012-0434-4

91. Jia W, Sander AJ, Jia G, Ni M, Liu X, Lu R, et al. Vascular endothelial growth inhibitor (VEGI) is an independent indicator for invasion in human pituitary adenomas. Anticancer Res. (2013) 33:3815-22. doi: 10.1007/s11839-013-0432-4

92. Miyajima K, Takekoshi S, Itoh J, Kakimoto K, Miyakoshi T, Osamura RY. Inhibitory effects of Anti-VEGF antibody on the growth and angiogenesis of estrogen-induced pituitary prolactinoma in fischer 344 rats: animal model of VEGF-targeted therapy for human endocrine tumors. Acta Histochem Cytoc. (2010) 43:33-44. doi: 10.1267/ahc.09034

93. Cohen AB, Lessell S. Angiogenesis and pituitary tumors. Semin Ophthalmol. (2009) 24:185-9. doi: 10.1080/08820530902805651

94. Ortiz LD, Syro LV, Scheithauer BW, Ersen A, Uribe H, Fadul CE, et al. Anti-VEGF therapy in pituitary carcinoma. Pituitary. (2012) 15:445-9. doi: $10.1007 / \mathrm{s} 11102-011-0346-8$
95. Touma W, Hoostal S, Peterson RA, Wiernik A, SantaCruz KS, Lou E. Successful treatment of pituitary carcinoma with concurrent radiation, temozolomide, and bevacizumab after resection. J Clin Neurosci. (2017) 41:75-7. doi: 10.1016/j.jocn.2017.02.052

96. Dworakowska D, Wlodek E, Leontiou CA, Igreja S, Cakir M, Teng $M$, et al. Activation of RAF/MEK/ERK and PI3K/AKT/mTOR pathways in pituitary adenomas and their effects on downstream effectors. Endocr Relat Cancer. (2009) 16:1329-38. doi: 10.1677/ERC09-0101

97. Sajjad EA, Zielinski G, Maksymowicz M, Hutnik L, Bednarczuk T, Wlodarski P. mTOR is frequently active in GH-secreting pituitary adenomas without influencing their morphopathological features. Endocr Pathol. (2013) 24:11-9. doi: 10.1007/s12022-012-9230-y

98. Rubinfeld H, Shimon I. PI3K/Akt/mTOR and Raf/MEK/ERK signaling pathways perturbations in non-functioning pituitary adenomas. Endocrine. (2012) 42:285-91. doi: 10.1007/s12020-012-9682-3

99. Chen R, Duan J, Li L, Ma Q, Sun Q, Ma J, et al. mTOR promotes pituitary tumor development through activation of PTTG1. Oncogene. (2017) 36:979-88. doi: 10.1038/onc.2016.264

100. Monsalves E, Juraschka K, Tateno T, Agnihotri S, Asa SL, Ezzat $S$, et al. The PI3K/AKT/mTOR pathway in the pathophysiology and treatment of pituitary adenomas. Endocr Relat Cancer. (2014) 21:R331-44. doi: 10.1530/ERC-14-0188

101. Lee M, Wiedemann T, Gross C, Leinhauser I, Roncaroli F, Braren R, et al. Targeting PI3K/mTOR signaling displays potent antitumor efficacy against nonfunctioning pituitary adenomas. Clin Cancer Res. (2015) 21:3204-15. doi: 10.1158/1078-0432.CCR-15-0288

102. Sukumari-Ramesh S, Singh N, Dhandapani KM, Vender JR. mTOR inhibition reduces cellular proliferation and sensitizes pituitary adenoma cells to ionizing radiation. Surg Neurol Int. (2011) 2:22. doi: 10.4103/2152-7806.77029

103. Dai C, Zhang B, Liu X, Ma S, Yang Y, Yao Y, et al. Inhibition of PI3K/AKT/mTOR pathway enhances temozolomide-induced cytotoxicity in pituitary adenoma cell lines in vitro and xenografted pituitary adenoma in female nude mice. Endocrinology. (2013) 154:1247-59. doi: 10.1210/en.2012-1908

104. Donovan LE, Arnal AV, Wang SH, Odia Y. Widely metastatic atypical pituitary adenoma with mTOR pathway STK11(F298L) mutation treated with everolimus therapy. CNS Oncol. (2016) 5:203-9. doi: 10.2217/cns-2016-0011

105. Grullich C. Immunotherapy as modern tumor treatment. Radiologe. (2017) 57:822-5. doi: 10.1007/s00117-017-0298-8

106. Hazrati SM, Aghazadeh J, Mohtarami F, Abouzari M, Rashidi A. Immunotherapy of prolactinoma with a $\mathrm{T}$ Helper 1 activator adjuvant and autoantigens: a case report. Neuroimmunomodulat. (2007) 13:205-8. doi: $10.1159 / 000100405$

107. Lu J, Adam B, Jack AS, Lam A, Broad RW, Chik CL. Immune cell infiltrates in pituitary adenomas: more macrophages in larger adenomas and more T cells in growth hormone adenomas. Endocr Pathol. (2015) 26:263-72. doi: 10.1007/s12022-015-9383-6

108. Topalian SL, Hodi FS, Brahmer JR, Gettinger SN, Smith DC, McDermott $\mathrm{DF}$, et al. Safety, activity, and immune correlates of anti-PD-1 antibody in cancer. N Engl J Med. (2012) 366:2443-54. doi: 10.1056/NEJMoa 1200690

109. Mei Y, Bi WL, Greenwald NF, Du Z, Agar NY, Kaiser UB, et al. Increased expression of programmed death ligand 1 (PD-L1) in human pituitary tumors. Oncotarget. (2016) 7:76565-76. doi: 10.18632/oncotarget. 12088

Conflict of Interest Statement: The authors declare that the research was conducted in the absence of any commercial or financial relationships that could be construed as a potential conflict of interest.

Copyright (0 2019 Dai, Liu, Ma and Wang. This is an open-access article distributed under the terms of the Creative Commons Attribution License (CC BY). The use, distribution or reproduction in other forums is permitted, provided the original author(s) and the copyright owner(s) are credited and that the original publication in this journal is cited, in accordance with accepted academic practice. No use, distribution or reproduction is permitted which does not comply with these terms. 